\title{
CONCENTRAÇÃO HIDROGENIÔNICA DO LEITE DE OVELHAS: INFLUENCIA DA MASTITE E DO CONGELAMENTO DA AMOSTRA
}

\author{
Maiara Garcia Blagitz, ${ }^{1}$ Camila Freitas Batista, ${ }^{2}$ Fernando Nogueira Souza, ${ }^{3}$ \\ Claudia Regina Stricagnolo, ${ }^{4}$ Viviani Gomes ${ }^{5}$ e Alice Maria Melville Paiva Della Libera ${ }^{6}$ \\ 1. Pós-graduanda na FMVZ/USP \\ 2. Pós-graduanda na FMVZ/USP \\ 3. Pós-graduanda na FMVZ/USP \\ 4. Técnica do laboratório da FMVZ/USP \\ 5. Professora Doutora da UFPR \\ 6. Professora doutora da FMVZ/USP.
}

RESUMO

A mensuração do $\mathrm{pH}$ do leite é um dos procedimentos mais importantes e frequentes na prática bioquímica. Essa variável aplica-se ao diagnóstico de doenças da glândula mamária, avaliação de rendimento industrial e identificação de síndromes metabólicas. O presente estudo teve por objetivo avaliar o efeito sobre o $\mathrm{pH}$, do congelamento do leite de ovelhas da raça Santa Inês proveniente de glândulas mamárias consideradas sadias e infectadas. Foram analisadas 183 amostras, sendo estas divididas em negativas (146) e positivas (37), segundo o resultado da cultura bacteriológica.
Dessas amostras determinou-se o $\mathrm{pH}$ no momento da coleta e após o congelamento a $-20^{\circ} \mathrm{C}$ por trinta meses. Observou-se redução do pH após o congelamento, sendo os valores maiores nas amostras que apresentaram resultado positivo na cultura bacteriológica. Houve maior decréscimo do $\mathrm{pH}$ após congelamento nas que apresentaram resultado positivo na cultura bacteriológica. $\mathrm{O}$ tipo de conservação das amostras lácteas deve ser considerado, bem como a análise de parâmetros que podem ser influenciados por essa variação.

PALAVRAS-CHAVES: pH, congelamento, leite, mastite, ovelhas.

ABSTRACT

\section{HYDROGEN ION CONCENTRATION IN EWE'S MILK: INFLUENCE OF MASTITIS AND SAMPLE FREEZING}

The measurement of $\mathrm{pH}$ in milk is one of the most important and frequent procedures performed in biochemistry practices. This variable is applied to the diagnosis of mammary gland disease, assessment of industrial yields, and identification of metabolic diseases. The objective of this study was to evaluate de effect of freezing the milk from healthy and infected mammary glands of Santa Ines ewes on the $\mathrm{pH}$. The bacteriological culture of 183 milk samples was analyzed resulting in 146 negative and
37 positive samples. From these, the hydrogen ion concentration was determined on sampling day and after freezing at $-20^{\circ} \mathrm{C}$ for 30 months. A reduction on $\mathrm{pH}$ was observed after freezing, and the bacteriological positive samples showed the highest $\mathrm{pH}$ values. A higher decrease of the $\mathrm{pH}$ after freezing was seen in positive samples. Thus, the kind of conservation of milk samples should be considered, as well as the results of parameters that could be influenced by such variation.

KEYWORDS: $\mathrm{pH}$, freezing, milk, ewes. 


\section{INTRODUÇÃO}

A mensuração do $\mathrm{pH}$ do leite, um dos procedimentos mais importantes e frequentes na prática bioquímica, representa a concentração total do íon hidrogênio originário de todas as fontes. Essa variável aplica-se ao diagnóstico da mastite (PYÖRÄLÄ, 2003), à avaliação de rendimento industrial (PARK et al., 2007) e à identificação de síndromes metabólicas.

A mensuração desse parâmetro é de crucial importância, considerando-se que o $\mathrm{pH}$ afeta a estrutura e a atividade de macromoléculas biológicas. Sempre que mecanismos reguladores do $\mathrm{pH}$ falham ou são sobrepujados, podem ocorrer danos celulares irreparáveis. Deve-se ressaltar que as atividades catalíticas de certas enzimas são sensíveis a variações do $\mathrm{pH}$. $\mathrm{O}$ controle biológico do $\mathrm{pH}$ dos fluidos corporais é de suma importância em todos os aspectos das atividades celulares e do metabolismo.

O leite é um fluido corporal caracterizado por um conjunto de emulsão diluída, dispersão coloidal e solução rica em compostos orgânicos e inorgânicos, sendo um sistema tamponante com baixa concentração de íon hidrogênio livre (CAVALCANTE et al., 2005). A leve acidez do leite está relacionada aos grupos ácidos livres de caseína, citrato e fosfato, além da presença de $\mathrm{CO}_{2}$ dissolvido (PYÖRÄLÄ, 2003; NUNES et al., 2008) e da concentração de lipídeos (CAVALCANTE et al., 2005), entre outros aspectos. PYÖRÄLÄ (2003), NUNES et al. (2008) e DE ALMEIDA et al. (2009) relataram aumento do $\mathrm{pH}$ durante a mastite, associado com o aumento da permeabilidade da glândula mamária aos componentes sanguíneos, o que faz que ocorra a migração de componentes alcalinos do sangue, destacando-se o íon bicarbonato.

No entanto, a constatação laboratorial de modificações do leite compatíveis com as condições clínicas do animal pode ser prejudicada pela distância entre o laboratório e a propriedade, pelo tempo entre a coleta e a análise ou pelo método de conservação da amostra. A refrigeração é um exemplo de importante medida para reduzir a possibilidade de multiplicação bacteriana que poderia mascarar o resultado, uma vez que o leite é um excelente meio de cultura. Dessa forma, a possibilidade de congelamento da amostra deixa o veterinário apreensivo quanto à confiabilidade dos resultados laboratoriais em relação àqueles que seriam obtidos se os exames fossem realizados imediatamente após a coleta (ARAÚJO et al., 1999). O congelamento favorece o diagnóstico em algumas circunstâncias. Por exemplo, com o intuito de minimizar resultados falsos-negativos na cultura bacteriológica de patógenos causadores de mastite, o congelamento de amostras lácteas tem sido sugerido, especialmente para Streptococcus agalactiae e Staphylococcus aureus (ZECCONI \& PICCININI, 1999; SOL et al., 2002), destacando-se o último, que apresenta aumento na ocorrência e na importância (ZECCONI \& PICCININI, 1999).

Com o decorrer do tempo, há tendência do aumento da acidez do leite, proveniente do desdobramento da lactose em ácidos, dos quais o mais importante é o ácido láctico, resultante da multiplicação da microbiota bacteriana, comumente encontrada no leite. Nesse fenômeno, influem consideravelmente os cuidados com a higiene e a temperatura aplicados durante a obtenção, manipulação e conservação do leite (TRONCO, 1997). CAVALCANTE et al. (2005) afirmaram que a atividade de lipases, mesmo a temperaturas entre 4 e $8{ }^{\circ} \mathrm{C}$, seria apenas reduzida, podendo ocasionar diminuição no $\mathrm{pH}$ devido à degradação de triacilgliceróis pelas lipases, produzindo ácidos graxos não esterificados (ácidos graxos livres).

As informações sobre os fatores que podem influenciar a análise dos componentes físico-químicos do leite de ovinos são restritas, especialmente para raças não especializadas na produção leiteira, como raça Santa Inês. Ressalta-se ainda que, para essas raças, a literatura carece de dados sobre a discriminação entre a glândula mamária sadia e a infectada.

O presente estudo teve por objetivo avaliar o $\mathrm{pH}$ do leite de ovelhas da raça Santa Inês proveniente de glândulas mamárias sadias e infectadas, além do efeito do congelamento sobre esse parâmetro.

\section{MATERIAL E MÉTODOS}

No presente estudo foram analisadas 183 amostras de leite de ovelhas Santa Inês primíparas e multíparas em diferentes fases da lactação, que foram divididas em negativas e positivas considerando-se o resultado da cultura bacteriológica como "padrão-ouro" (CONTRERAS et al., 2007).

Inicialmente, desprezaram-se os primeiros jatos de cada metade mamária. Logo em seguida, procedeu- 
-se à higienização do úbere e à assepsia do óstio do canal do teto; finalmente, realizou-se a coleta asséptica do leite.

No exame bacteriológico, as amostras de leite coletadas foram semeadas em placa de Petri contendo ágar-sangue de carneiro $(5 \%)$ e incubadas a $37^{\circ} \mathrm{C}$ por períodos de 24 a 48 horas. Posteriormente fez-se a identificação dos microrganismos, através de provas bioquímicas descritas por LENNETTE et al. (1985), seguida da classificação conforme critérios estabelecidos por KRIEG \& HOLT (1994).

A determinação da concentração hidrogeniônica foi realizada em peagômetro modelo B474 da Micronal ${ }^{\circledR}$, calibrado em temperatura ambiente com soluções de pH 7,0 e 4,0, sendo, no entanto, a análise realizada em dois momentos: coleta (M0) e após o congelamento (M1). Mantiveram-se as amostras congeladas à temperatura aproximada de $-20^{\circ} \mathrm{C}$ por um período de trinta meses.

A distribuição de Gaussian foi confirmada pelos testes de Kolmogorov e Smirnov. Posteriormente, os dados foram submetidos ao teste $\mathrm{t}$ para verificar as diferenças entre os grupos. Quando houve diferença significativa, realizou-se o teste $\mathrm{t}$ para amostras pareadas - no caso dos que apresentaram distribuição normal -, e o teste de Mann-Whitney, para os dados que não apresentaram distribuição de Gaussian. A análise estatística foi realizada utilizando o programa GraphPad Prisma 5.0 software (GraphPad Software, Inc., San Diego, CA, USA). Foram consideradas significantes as análises que apresentaram $\mathrm{P}<0,05$.

\section{RESULTADOS}

Foram observadas $146(79,78 \%)$ amostras negativas e $37(20,22 \%)$ amostras positivas na cultura bacteriológica. Destas, isolou-se apenas Staphylococcus spp. Os valores do $\mathrm{pH}$ encontrados na coleta $\mathrm{e}$ posteriormente ao congelamento das amostras (total), assim como a sua discriminação segundo o resultado do exame bacteriológico, estão apresentados na Tabela 1.

TABELA 1. Valores do $\mathrm{pH}$ na coleta e posteriormente ao congelamento nas amostras de leite de ovinos da raça Santa Inês, divididas em negativas e positivas conforme o resultado do exame bacteriológico

\begin{tabular}{lccc}
\hline Parâmetro/amostras & $\mathrm{pH}(\mathrm{M} 0)$ & $\mathrm{pH}(\mathrm{M} 1)$ & $\mathrm{P}$ \\
\hline Total & $6,71(6,22-7,66)$ & $6,57(6,04-7,92)$ & 0,0001 \\
Negativas & $6,70(6,22-7,66)$ & $6,51(6,04-7,92)$ & 0,0001 \\
Positivas & $6,82(6,53-7,60)$ & $6,58(6,17-7,15)$ & 0,0001 \\
\hline
\end{tabular}

M0: momento da coleta.

M1: após o congelamento.

Negativas: amostras negativas ao exame bacteriológico.

Positivas: amostras positivas ao exame bacteriológico.

P: valor de significância.

Ademais, os valores de $\mathrm{pH}$ das amostras negativas foi significantemente inferior ao das amostras positivas antes do congelamento $(\mathrm{P}=0,0036)$. Posteriormente ao congelamento, observou-se apenas uma tendência a menor $\mathrm{pH}$ nas amostras negativas $(\mathrm{P}=0,093)$. Ao comparar a diferença dos valores do $\mathrm{pH}$ antes e após o congelamento, observou-se maior decréscimo nas amostras positivas $(0,25)$ em relação com as amostras negativas $(0,19)(\mathrm{P}=0,0376)$.

$\mathrm{O}$ leite proveniente das metades mamárias consideradas infectadas apresentou maior $\mathrm{pH}$ que aquele oriundo das glândulas mamárias consideradas sadias, como descrito por NUNES et al. (2008) e DE ALMEIDA et al. (2009).

Os valores de $\mathrm{pH}$ do leite encontrados no presente trabalho são similares aos verificados nas amostras provenientes de glândulas mamárias sadias $(6,51$ a 6,71$)$ e infectadas $(6,63$ a 6,93$)$ em estudos desenvolvidos por BIANCHI et al., (2004), ALBENZIO et al., (2005), SOUZA et al., (2005), SANTOS et al., (2007), DE ALMEIDA et al., (2009). 
$\mathrm{O}$ aumento do $\mathrm{pH}$ observado nas glândulas mamárias consideradas infectadas indica aumento também da permeabilidade vascular e extravasamento de íons do compartimento sanguíneo para o leite como resultado do processo inflamatório (PYÖRÄLÄ, 2003; SANTOS et al., 2007; NUNES et al., 2008; DE ALMEIDA et al., 2009).

Além disso, observou-se redução do $\mathrm{pH}$ do leite oriundo de diferentes grupos (total, negativas e positivas) após o congelamento, o que corrobora o resultado encontrado por CAVALCANTE et al. (2005). Isso pode levar ao diagnóstico incorreto da mastite, se forem utilizados os valores de corte aplicados para o diagnóstico dessa enfermidade, principalmente considerando-se a maior redução no $\mathrm{pH}$ do leite proveniente de glândulas mamárias infectadas $(0,25)$ em relação às sadias $(0,19)$.

$\mathrm{O}$ fato pode ser explicado pelo desdobramento da lactose em ácidos, como o ácido láctico, pela ação de microrganismos presentes no leite, causadores de mastite ou até mesmo pela presença de lipases produzidas por essa microbiota que ocasionariam maior formação de ácidos graxos não esterificados; estes, em conjunto, resultariam na maior redução do $\mathrm{pH}$ (TRONCO, 1997; CAVALCANTE et al., 2005). Ademais, a maior permeabilidade nos casos de mastite ocasiona o influxo de enzimas hidrolíticas que modificam a composição láctea pela ruptura de moléculas proteicas e de gordura (KITCHEN, 1981). Enzimas proteolíticas presentes no leite durante processos infecciosos podem levar à ruptura da membrana de glóbulos de gordura, predispondo a gordura à degeneração pelas lipases (AZZARA \& DIMICK, 1985)

\section{CONCLUSÃO}

O leite proveniente das metades mamárias consideradas infectadas apresentou maior $\mathrm{pH}$ que aquele oriundo das glândulas mamárias consideradas sadias. $\mathrm{O}$ congelamento ocasionou redução do $\mathrm{pH}$ do leite.

\section{REFERÊNCIAS}

ALBENZIO, M.; CAROPRESE, M.; SANTILLO, A.; MARINO, R.; MUSCIO, A.; SEVI, A. Proteolytic patterns and plasmin activity in ewe's affected by somatic cell count and stage of lactation. Journal of Dairy Research, v. 72, p. 86-92, 2005.
ARAÚJO, W. P.; YUZAMA, H. C. Y.; DELLA LIBERA, A. M. M. P. Efeito do tempo e da temperatura de conservação sobre o número de bactérias, de células somáticas e características físico-quimícas de amostras de leite. Revista Brasileira de Medicina Veterinária, v. 21, n. 3, p. 104-107, 1999.

AZZARA, C. D.; DIMICK, P. S. Lipoprotein lipase activity of milk from cows with prolonged subclinical mastitis. Journal of Dairy Science, v. 68, p. 3.171-3.175, 1985.

BIANCHI, L.; BOLLA, A.; BUDELLI, E.; CAROLI, A.; CASOLI, C.; PAUSELLI, M.; DURANTI, E. Effect of udder health status and lactation phase on characteristics of Sardinian ewe milk. Journal of Dairy Science, v. 87, p. 2.401-2.408, 2004.

CAVAlCANTE, J. L. P.; TELlES, F. J. S.; PEIXOTO, M. M. L. V.; RODRIGUES, R. C. B. Uso da acidez titulável no controle de qualidade do leite humano ordenhado. Ciências Tecnológicas Alimentares, v. 25, n. 1, p. 103-108, 2005.

CONTRERAS, A.; SIERRA, D.; SÁNCHEZ. A.; CORRALES, J. C.; MARCO, J. C.; PAAPE, M. J.; GONZALO, C. Mastitis in small ruminants. Small Ruminant Research, v. 68, p. 145-153, 2007.

DE ALMEIDA, M. Z.; DE OLIVEIRA, L. G. L; AFONSO, J. A. B.; LÁZARO, N. S.; MENDONÇA, C. L. Influência da infecção intramamária sobre as características físico-químicas do leite de ovelhas da raça Santa Inês. Ciência Animal Brasileira, supl. 1, p. 760-765, 2009. In: Anais do VIII Congresso Brasileiro de Buiatria, 2009. Disponível em: <http://www.revistas.ufg.br/index.php/vet/ article/view/7897/5745 >. Acesso em: ?????

KITCHEN, B. J. Review of the progress of dairy science: bovine mastitis: milk compositional changes and diagnostic tests. Journal of Dairy Research, v. 48, p. 167-188, 1981.

KRIEG, N. R.; HOLT, J. C. Bergey's manual of systematic bacteriology. 9. ed. Baltimore: Willians \& Wilkins, 1994. 1368 p. LENNETE, E. M.; BALOWS, A.; HANSLER, JR., W. J. Manual of clinical microbiology. 4. ed. Washington: American Society of Microbiology, 1985. 1149 p.

NUNES, G. R.; BLAGITZ, M. G.; FREITAS, C. F.; SOUZA, F. N.; RICCIARDI, M.; STRICAGNOLO, C. R.; SANCHES, B. G. S.; AZEDO, M. R.; SUCUPIRA, M. C. A.; DELLA LIBERA, A. M. M. P. Avaliação de indicadores inflamatórios no diagnóstico da mamite ovina. Arquivos do Instituto Biológico, v. 75, n. 3, p. 271-278, 2008.

PARK, Y. W.; JUÁREZ, M.; RAMOS, M.; HAENLEIN, G. F. W. Physico-chemical characteristics of goat and sheep milk. Small Ruminant Research, v. 68, p. 88-113, 2007.

PYÖRÄLÄ, S. Indicators of inflammation in the diagnosis of mastitis. Veterinary Research, v. 34, p. 565-578, 2003. 
SANTOS, R. A.; MENDONÇA, C. L.; AFONSO, J. A. B.; SIMÃO, L. C. S. Aspectos clínicos e características do leite em ovelhas com mastite induzida experimentalmente com Staphylococcus aureus. Pesquisa Veterinária Brasileira, v. 27, n. 1, p. 6-12, 2007.

SOL, J.; SAMPIMON, O. C.; HARTMAN, E.; BARKEMA, $\mathrm{H}$. W. Effect of preculture freezing and incubation on bacteriological isolation from subclinical mastitis samples. Veterinary Microbiology, v. 85, p. 241-249, 2002.
Produção, composição química e características físicas do leite de ovinos da raça Corriedale. Revista Brasileira de Agrociências, v. 11, p. 73-77, 2005.

TRONCO, V. M. Manual para inspeção da qualidade do leite. Santa Maria: Editora UFSM, 1997.166 p.

ZECCONI, A.; PICCININI, R. Teoria e prática de controle de mamite por Staphylococcus aureus. Napagma, n. 5, p. 4-11, 1999.

SOUZA, A. N. C. K. O.; OSÓRIO, M. T. M.; OSÓRIO, J. C. S.;

OLIVEIRA, N. M.; VAZ, C. M. S.; SOUZA, M.; CORRÊA, G. F.

Protocolado em: 24 mar. 2010. Aceito em: 21 jan. 2011. 